ISSN 2442-3041

Math Didactic: Jurnal Pendidikan Matematika

Vol. 2, No. 3, September - Desember 2016

(c) STKIP PGRI Banjarmasin

\title{
PEMBELAJARAN MATEMATIKA DALAM PERSPEKTIF KEKINIAN
}

\author{
Marsigit \\ Jurusan Pendidikan Matematika, FMIPA Universitas Negeri Yogyakarta \\ marsigitina@yahoo.com
}

\begin{abstract}
Abstrak: Pada Konaspi VIII di Jakarta, 13 Oktober 2016, terdapat pokok-pokok pemikiran penting perihal revitalisasi pendidikan di Indonesia dewasa ini terkait dengan kondisi LPTK dan masa depan guru. Kementerian PPN melalui Deputi Menteri PPN/Kepala Bappenas Bidang Pembangunan Manusia, Masyarakat, dan Kebudayaan BAPPENAS (Subandi Sardjoko, 2016) menguraikan bahwa penguatan lembaga pendidikan tinggi keguruan melalui revitalisasi LPTK dilakukan agar dapat mengembangkan program akademik, untuk dapat melahirkan guru-guru yang berkualitas. UU No. 14/2005 tentang Guru dan Dosen, dalam Bab Ketentuan Penutup Pasal 82 mengatur bahwa Guru yang belum memiliki kualifikasi akademik dan sertifikat pendidik wajib memenuhi kualifikasi akademik dan sertifikat pendidik paling lambat pada tahun 2015. Pesan pokok UU Guru dan Dosen adalah untuk meningkatkan kualitas pendidikan melalui peningkatan kualitas guru. Sementara, ditataran makro atau dunia, Jika kita menuju hilirnya Filsafat, kita akan menemukan Pendidikan Berbasis Rasio atau Berbasis Kognitif, dengan sifat-sifat ikutan yang dapat diturunkan sebagai atau berbentuk Cognitive-Based Education, Anti-Spiritualisme, Dunia Parsial dan Hedonisme. Dalam era Kontemporer (AFTA), terdapat main-set yang cukup kuat dan signifikan bahwa semua pengambil kebijakan Pendidikan di Indonesia akan mengimplementasikan Pendidikan Berbasis Pasar, yang dengan sendirinya akan mencari hakekat kebenaran ada di dalam Pasar. Dengan metode yang sama seperti sudah dilakukan di atas, dapat disimpulkan bahwa Pendidikan Berbasis Pasar dengan sendirinya bersifat Anti-Spiritualisme, dengan sifat-sifat ikutan yang dapat diturunkan sebagai Reduksionisme, Eksploitasi Vital, Kompetisi Mutlak, Egosentrik, Hegemoni, Dunia Terpotong, Materialisme, Pragmatisme, Hedonisme, dan Pendidikan Laskar. Pendidikan Konseratif Mutlak mempunyai sifat Reduksionisme, Eksploitasi Vital, Monokulturisme, Egosentrik, dan Ethical Closed-ended Mutlak (Nilai Budaya Tertutup Mutlak).
\end{abstract}

Kata kunci: pendidikan matematika, perspektif kekinian.

\section{Posisi Guru (Matematika) di Tengah Revitalisasi LPTK}

Hasil studi oleh Bappenas
menunjukkan bahwa sertifikasi yang
dilakukan sampai saat ini baru berpengaruh
positif pada peningkatan kesejahteraan guru

dan belum berdampak pada peningkatan kualitas guru. Kondisi guru : 24,3\% guru belum memenuhi kualifikasi kademik; $47,4 \%$ guru belum memiliki sertifikat pendidik. Revitalisasi LTPK perlu diarahkan pada pengembangan program akademik dan pembaruan kurikulum, yang mendukung upaya peningkatan empat kompetensi pokok seperti diamanatkan UU No. 14/2005, yaitu: 
(1) pedagogis, (2) kepribadian, (3) profesional, (4) sosial. LPTK semestinya tidak terobsesi dengan penerimaan mahasiswa dalam jumlah besar. Sebaliknya, LPTK harus lebih mengutamakan kualitas melalui perbaikan program akademik (e.g. pembaruan \& pengembangan kurikulum, program studi, etc.), peningkatan kualitas tenaga akademik (dosen, peneliti), dan perkuatan kelembagaan. Berikut kami nukilkan pokok-pokok pemaparan tentang revitalisasi pendidikan keguruan, oleh Bappenas, sebagai berikut (Subandi Sardjoko, 2016):

1. Meningkatkan kapasitas LPTK untuk memperbaiki mutu pendidikan keguruan melalui PPG berasrama, yang tercermin pada peningkatan kompetensi guru dalam subject knowledge dan pedagogical knowledge.

2. Meningkatkan profesionalisme, kualitas, dan akuntabilitas guru melalui program induksi dan praktik mengajar berbasis penelitian di sekolah, untuk memperbarui ilmu pengetahuan, mendalami ilmu pedagogi, dan mengembangkan metode pembelajaran.

3. Reorientasi program pre-service education di LPTK yang sesuai dengan tuntutan kebutuhan masyarakat akan guru-guru yang memenuhi kualifikasi akademik dan memiliki kompetensi tinggi (profesional).

4. Memantapkan program Pendidikan Profesi Guru (PPG) berasrama untuk memperbaiki model pendidikan keguruan.

5. Seiring dengan semakin meningkatnya minat lulusan Sekolah Menengah untuk menempuh pendidikan tinggi di universitas LPTK, perlu dilakukan seleksi calon mahasiswa yang ketat untuk menyaring calon-calon guru yang berkualitas.

6. Seleksi penerimaan calon mahasiswa LPTK harus ketat dan menyaring mereka yang benar-benar punya passion di bidang keguruan untuk dididik menjadi guru profesional.

7. Perlu ada refleksi 16 tahun transformasi IKIP menjadi Universitas: beban ganda sebagai LPTK yang mendidik calon guru dan peran sebagai lembaga pendidikan tinggi non-kependidikan;

8. Selama ini, kritik yang seringkali muncul adalah LPTK belum sepenuhnya mampu melahirkan guruguru kompeten yang menguasai mata pelajaran. Lulusan-lulusan LPTK dinilai mahir dalam hal pemahaman dan penguasaan metodologi pengajaran (pedagogical method), namun kurang canggih dalam penguasaan substansi bahan-ajar (subject knowledge);

9. Kementerian Riset, Teknologi, dan Pendidikan Tinggi harus melakukan evaluasi menyeluruh terhadap kinerja LPTK. Perlu dipastikan kemampuan LPTK dalam melahirkan guru-guru berkualitas, yang menguasai tiga kompetensi utama: subject content knowledge, pedagogical knowledge \& teaching skills.

10. Kemristekdikti harus mampu mengendalikan pertumbuhan LPTK swasta, termasuk jumlah mahasiswa dengan mempertimbangkan keseimbangan antara supply \& demand terkait guru.

11. Meningkatan kualitas pendidikan dalam jabatan (in-service education) untuk memberi kesempatan bagi para guru dalam mengembangkan kemampuan profesional secara berkelanjutan.

12. Pelatihan guru bidang mata pelajaran harus dirancang bukan saja untuk melakukan pendalaman materi-ajar, tetapi juga untuk meningkatkan keterampilan mengajar.

13. Peningkatan kualitas guru hanya bisa ditingkatkan melalui program continuous professional development, sehingga para guru tidak pernah berhenti berinovasi dalam mengembangkan proses pengajaran dan pembelajaran. 
14. Revitalisasi LPTK yang bertujuan untuk meningkatkan kualitas pendidikan keguruan harus mulai dilakukan pada tahun pertama pelaksanaan RPJMN 2015-2019;

15. Pengembangan model pendidikan guru berasrama melalui Pendidikan Profesi Guru (PPG) untuk melahirkan guru-guru berkualitas;

16. Penetapan standar lembaga pendidikan keguruan dan perkuatan LPTK (e.g. SDM, sarpras, teaching school, anggaran);

17. Penataan sistem penerimaan mahasiswa calon guru di universitas LPTK yang selektif;

18. Rancangan model pengembangan profesi berkelanjutan untuk meningkatkan kompetensi \& jaminan pengembangan karir profesional guru;

19. Kebutuhan anggaran dan pemanfaatannya untuk mendukung revitalisasi LPTK.

Sementara Minna Mäkihonko (2016) menyatakan kedudukan sentral guru dalam revitalisasi LPTK dengan pemahamanpemahaman akan pentingnya unsur-unsur pendidikan inovatif meliputi:

1. Student centered approach,

2. Evidence-based teaching practices

3. Subject specific pedagogy

4. Addressing the diversity in classrooms

5. Supporting students 'wellbeing and motivation

6. Mentoring teaching practice

7. Active rather than passive learning

8. Deep learning and understanding

9. Address diversity of learning

10. Responsibility and accountability on the part of the student

11. Assume responsibility in the supervision and tutoring of student teachers during their internship

12. Act as leading educational institutions in the provision of teaching and learning
13. Be familiar with the central scientific, theoretical and ethical questions of mentoring

14. Be able to use various interactive mentoring practice, including media and ICT

15. Carry out a mentoring process that leads to professional growth towards full teacher accreditation.

16. Motivation and commitment of the applicant to the field of education and teaching

17. Potential of the applicant to successfully meet the learning aims and complete the studies

18. Interaction, communication, cooperation, and problem solving skills.

19. A dialogue between teacher and learner

20. Mutual respect within the learnerteacher relationship

21. A reflective approach to teaching and learning process

\section{Pengembangan Kompetensi Guru Matematika Dalam Kerangka Kurikulum Nasional}

\begin{tabular}{llr}
\multicolumn{2}{c}{ Seperti diketahui bahwa secara } \\
eksplisit & pendekatan & Saintifik \\
direkomendasikan untuk metode
\end{tabular} pembelajaran (dengan didukung atau dikombinasikan dengan metode lain yang selaras) dalam kerangka Kurikulum 2013. Sebelum diuraikan tentang implementasi dan contoh-contohnya, maka di sini akan dilakukan sintesis tentang adanya dikotomi pemikiran Saintifik dan Tidak Saintifik. Pendekatan saintifik yang terdiri dari sintak: a. mengamati; b. menanya; c. mengumpulkan informasi; d. mengasosiasi; dan e. mengkomunikasikan. Pembelajaran dengan pendekatan Saintifik tetaplah berbasis Kompetensi sesuai dengan jiwa dan semangat Kurikulum 2013. Fakta atau fenomena merupakan objek keilmuan yang digunakan untuk membangun (Ilmu) Pengetahuan dengan pendekatan Saintifik yang melibatkan unsur logika dan pengalaman. Segala macam kira-kira, 
khayalan, legenda, atau dongeng dapat berfungsi untuk memperkuat landasan pikiran dan pengalaman. Pendekatan Saintifik dapat diselenggarakan dalam kerangka Konstruksivisme, yaitu memberi kesempatan peran siswa untuk membangun pengetahuan/konsepnya melalui fasilitasi guru. Terminologi "Penjelasan guru-respon siswa" bertentangan dengan semangat Saintisme yaitu kemandirian untuk menemukan pengetahuannya. Pemikiran subjektif diperlukan untuk memperkokoh karakter memperoleh Sensasi Pengalaman. Penalaran yang menyimpang perlu disadari dan dicarikan solusi dan penjelasannya untuk memperkokoh konsep yang telah dibangunnya.

Indikator atau kriteria sifat non Ilmiah tidak serta merta dapat diturunkan dengan menegasikan sifat Ilmiah. Pendekatan Ilmiah bersintak (sesuai dengan referensinya), maka sifat Ilmiah tidak serta merta secara rigid identik dengan sintak-sintaknya. Untuk memperoleh sintak Ilmiah terkadang subjek didik melakukan hal-hal yang dapat dikategorikan sebagai non ilmiah, misal kekeliruan mengobservasi, dan mengambil kesimpulan. Kesimpulan yang belum benar mungkin terjadi walaupun siswa sudah menggunakan sintak Saintifik. Peran intuisi sangat penting bai sebagai Intuisi Berpikir maupun sebagai Intuisi Pengalaman. Akal sehat sangat bermanfaat sebagai dimulainya kesadaran untuk mempersepsi objek berpikir. Kegiatan coba-coba secara ontologis bermakna sebagai kegiatan interaksi antara pikiran dan pengalaman, antara logika dan faktanya, antara analitik dan sintetik, dan antara a priori dan a posteriori. Berpikir kritis adalah berpikir reflektif sampai pada kemampuan mengambil keputusan secara benar. Fenomenologi sebagai kerangka filosofis pendekatan Saintifik. Hermenitika sebagai pendekatan epistemologi pendekatan Saintifik.

Untuk mendukung palaksanaan Kurikulum 2013, guru perlu mengembangkan 10 (sepuluh) langkah: a. Mengembangkan RPP yang memfasilitasi siswa untuk membangun hidup (ilmu)-Lile Skill, b. Mengembangkan Apersepsi sebagai kegiatan siswa dan bukan kegiatan guru, c.
Mengembangkan Kegiatan Diskusi Kelompok, karena hakekat Ilmu bagi siswa SD dan SMP adalah Kegiatan Diskusi, d. Mengembangkan Skema Pencapaian Ketrampilan Hidup (lebih tinggi dari Kompetensi), e. Mengembangkan LKS yang memfasilitasi siswa agar memperoleh Ketrampilan Hidup (LKS harus dibuat sendiri oleh guru dan bukan dari membeli; LKS bukan sekedar kumpulan soal), f. Mengembangkan kegiatan assessment (bukan sekedar penilaian), berupa Portfolio dan Authentics Assessment, g, . Mengembangkan Kegiatan Refleksi Siswa untuk menyampaikan dan menjelaskan kesimpulan diskusi kelompoknya, $h$. Mengembangkan dan mendorong agar Siswa sendiri yang memperoleh Kesimpulan, i. Mengembangkan Media atau Alat Peraga yang menunjang, $\mathrm{j}$. Menembangkan Metode Pembelajaran yang Dinamis, Kreatif, Fleksibel, dan Kontekstual.

\section{Pengembangan Model Pembelajaran Matematika}

\section{Pengembangan Model}

Dari uraian yang sudah diberikan, dapat ditarik pelajaran bahwa untuk dapat mengembangkan suatu pembelajaran matematika, seorang guru dituntut agar memahami dasar-dasar atau filosofi pendidikan serta teori-teori yang menyertainya.

\section{Pengembangan Pembelajaran Matematika Melalui Learning Trajectory}

Skema pencapaian kompetensi belajar matematika dipengaruhi oleh kesadaran guru, sekolah atau sistem pendidikan tentang adanya bermacammacam paradigma pendidikan dan politikpendidikan yang melatar belakangi praktik kependidikannya. Karakteristik skema pencapaian kompetensi belajar matematika yang dikembangkan, menggambarkan keseluruhan sistem dan dunia pendidikan. Ernest P. (1995) menerangkan bahwa perbedaan politik dan 
ideologi pendidikan akan mempengaruhi kepada tujuan pendidikan, teori-teori mengajar dan belajar, pengembangan sumber mengajar dan belajar, pengembangan media dan alat peraga, serta pengembangan penilaian pembelajaran. Mengingat hal tersebut di atas, maka sebelum mengembangkan skema pencapaian kompetensi belajar, perlu terlebih dulu dilakukan karakterisasi konteks pendidikannya; dalam hal ini, konteks pendidikan matematika Indonesia yang secara formal digariskan dengan Kurikulum 2013 dan secara substansial merupakan sejarah kebiasaan praktek-praktek kependidikan. pandangan terakhir dikategorikan sebagai berada di wilayah kontek pendidikan inovatif yaitu Progressive dan Public Educator. Baik secara formal maupun substansial, praktek kependidikan di Indonesia dapat dikarakterisasi sebagai lebih dominan bersifat konvensional atau tradisional, walaupun mempunyai cita-cita menuju kependidikan inovatif yaitu dengan ditetapkannya Pancasila sebagai landasan pendidikan dalam wujud Demokrasi Pancasila.

Mengingat uraian di atas maka dapat dipahami bahwa Skema Pencapaian Kompetensi Belajar Matematika yang akan dikembangkan mempunyai dua macam

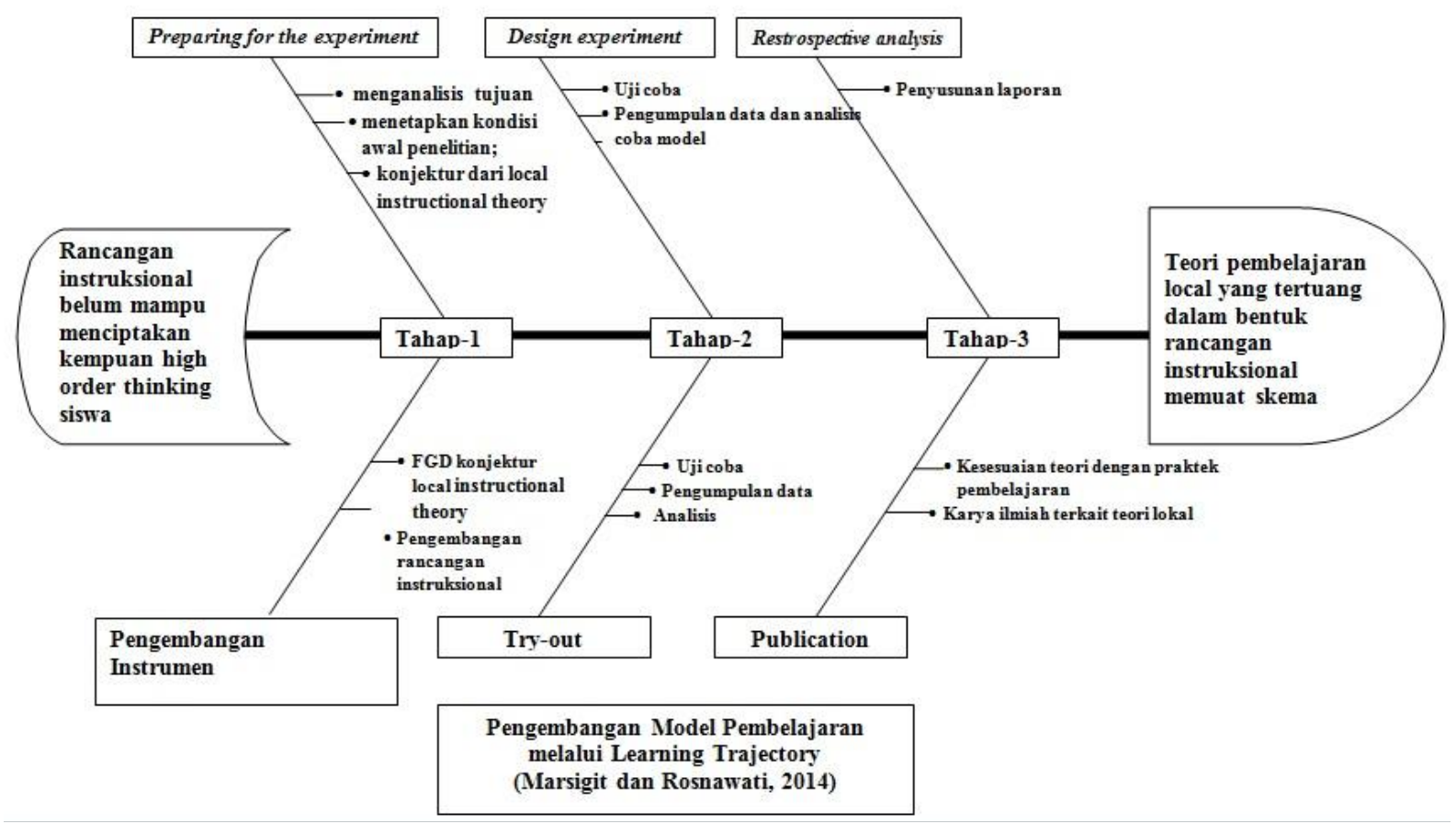

Ditinjau dari pandangan tentang hakikat matematika, Ernest P. (ibid) membedakan tiga kelompok pertama sebagai konteks pendidikan yang berasumsi matematika sebagai Struktur Pengetahuan, Struktur Kebenaran, dan Bangunan Ilmu; dan dua kelompok kedua yang memandang matematika sebagai Kreativitas Berpikir dan Kegiatan Sosial. Tiga pandangan pertama dikategorikan sebagai berada di dalam konteks pendidikan yang bersifat konvensional atau tradisional, meliputi Technological Pragmatism, Industrial Trainer, dan Old Humanism. Sedangkan dua landasan yaitu: 1. Secara formal berlandaskan konteks Kurikulum 2013 dan secara substansial berlandaskan tradisi atau kebiasaan, 2. Secara normatif berdasarkan referensi universal dan secara substansial berdasarkan pada hakekat komponen pembelajaran meliputi hakekat matematika, hakekat belajar matematika, hakekat metode pembelajaran, hakekat sumber belajar dan hakekat penilaian. NCTM (2014) menggariskan terdapat dua macam kompetensi matematika di sekolah yaitu Kompetensi Isi Matematika dan Kompetensi Proses Matematika. Kompetensi Isi Matematika meliputi Bilangan dan 
Operasinya, Aljabar, Geometri, Pengukuran, Analisis Data dan Probabilitas. Sedangkan Kompetensi Proses Matematika meliputi Pemecahan Masalah, Penalaran dan Bukti, Komunikasi Matematika, Koneksi Matematika dan Representasi Matematika.

Pada Bilangan dan Operasinya, siswa diharap mampu memahami pengertian bilangan, melakukan operasi dan perhitungan menggunakan bilangan. Untuk siswa tingkat SMP, diharap mampu menguasai bilangan bulat dan juga bilangan pecah dan melakukan operasi dengan berbagai cara serta dapat menggunakan alat bantu seperti Kalkulator. Pada Aljabar, siswa diharap mampu melakukan Penalaran Aljabar dan melakukan investigasi adanya hubungan antara variabel dalam bentuk persamaan atau perttidaksamaan. Pada Geometri, siswa diharap mampu mengidentifikasi sifat-sifat bangun geometri, memahami hubungannya, melakukan visualisasi, penalaran bidang dan keruangan, model-model geometri serta model-model geometri untuk memecahkan persoalan matematika. Pada Pengukuran, diharap siswa memahami atribut, satuan, sistem pengukuran, proses mengukur, teknik mengukur, dan dapat menggunakan alat dan rumus untuk menentukan hasil pengukuran. Pada Analisis Data dan Probabilitas, siswa diharap mengamati, menanya, mengumpulkan, mengorganisasi, dan menyajikan data-data untuk menjawab pertanyaan-pertanyaan. Siswa juga diharap mampu menggunakan langkah-langkah Statistika untuk menganalisis data, mengolah dan menerjemahkan artinya.

Pada Pemecahan Masalah, siswa diharap merumuskan persoalan ke dalam kalimat matematika, dan memecahkannya menggunakan berbagai metode matematika. Siswa diharap dapat menerapkan suatu metode yang telah digunakan kasus lain untuk memecahkan masalah yang sama. Kegiatan pemecahan masalah melibatkan cara berpikir, rasa ingin tahu, rasa percaya diri baik di dalam maupun di luar kelas. Pada Penalaran Matematika dan Bukti, siswa dapat menganalisis pola-pola yang ada, strukturstruktur, dan ketentuan atau syarat-syarat baik yang ada dalam fenomena sehari-hari maupun yang ada dalam matematika itu sendiri. Komunikasi Matematika merupakan kegiatan untuk tukar menukar ide atau gagasan agar siswa dapat melakukan klarifikasi dan pemahaman yang lebih mendalam. Komunikasi Matematika dapat dilakukan dengan cara menulis, menjelaskan secara lisan, atau menggunakan simbol atau gambar matematika. Pada Koneksi Matematika, siswa diharap mampu menguhubungkan satu kosep dengan konsep yang lain untuk memperoleh struktur matematika yang lebih lengkap atau komprehensif. Pada Representasi, siswa diharapkan mampu menyajikan matematika ke dalam berbagai cara misalnya gambar, benda konkrit, tabel, grafik, bilangan atau huruf-huruf.

Learning Trajectory adalah alur berpikir siswa tentang matematika, perkembangan dan bentuknya. Dikarenakan setiap siswa mempunyai potensi dan sifat yang berbeda dalam memikirkan matematika, maka learning trajectory bersifat personal dan kontekstual. Dari sifat personal dan kontekstual tersebut, maka dapat diusahakan untuk mencari pola-pola pada komunitas atau kelompok siswa pada suatu konteks pembelajaran matematika tertentu. Mengingat hal tersebut maka diaungkapkannya learning trajectory akan membawa manfaat yang besar bagi guruguru matematika. Clements \& Sarama, 2009, p. 2 dalam Dian Armanto \& Max Stephens (2011) menyatakan :" In learning mathematics, students follow natural development progressions in learning and development. They follow development progressions in learning mathematical ideas and skills in their own way"

Untuk dapat mengungkap learning trajectory siswa, maka guru, dalam mengajar, perlu melakukan kegiatan observasi belajar siswa dan menafsirkannya sesuai dengan teori yang ada. Dapat dipahami bahwa learning trajectory siswa dipengaruhi oleh asumsi dasar tentang hakekat dan kompetensi matematika sekolah, baik kompetensi konten matematika maupun kompetensi proses matematika. Teori belajar yang sesuai dengan pengembangan learning trajectory adalah teori belajar Konstruktivis dan Saintifik (Simon, 1995: ibid). Secara 
formal, learning trajectory meliputi tiga komponen yaitu : Kompetensi Matematika Sekolah; Pengembangan Alur Berpikir siswa berdasar kompetensi yang ditetapkan; serta, aktivitas dan tugas belajar sesuai dengan pengembangan learning trajectory.

\section{Pengembangan Matematika Etnomatematika}

\section{Pembelajaran} Berbasis

Shirley (2014) berpandangan bahwa sekarang ini bidang etnomatematika, yaitu matematika yang tumbuh dan berkembang dalam masyarakat dan sesuai dengan kebudayaan setempat, dapat digunakan sebagai pusat proses pembelajaran dan metode pengajaran, walaupun masih relatif baru dalam dunia pendidikan. Etnomatematika membutuhkan interpretasi yang dinamis. Sebagaimana dikemukakan oleh D'Ambrosio (1987) bahwa "The term requires a dynamic interpretation because it describes concepts that are themselves neither rigid nor singular-namely, ethno and mathematics".

\section{a. Etnomatematika Konteks Candi Prambanan (M Kamaludin, 2014)}

Dari hasil observasi lapangan ethnomatematika di Candi Prambanan pada hari Jumat, 24 April 2015 diperoleh data data dalam bentuk foto dokumentasi mengenai bagian - bagian Candi Prambanan yang terkait dengan ethnomatematika, sebagai berikut:

\begin{tabular}{|l|l|}
\hline Foto Benda & Identifikasi Benda \\
\hline & $\begin{array}{l}\text { Nama Benda: } \\
\text { Candi Brahma } \\
\text { Lokasi Benda: } \\
\text { Di pelataran utama } \\
\text { Candi Prambanan } \\
\text { Bahan: Batu }\end{array}$ \\
\hline
\end{tabular}

\section{b. Etnomatematika Konteks Candi Borobudur (Dyah Wahyu Utami, dkk)}

\begin{tabular}{|l|c|}
\hline $\begin{array}{l}\text { Artefak Yang } \\
\text { Mengandung } \\
\text { Matematis }\end{array}$ & $\begin{array}{c}\text { AspekMatematikaS } \\
\text { Unsur } \\
\text { ekolah Yang } \\
\text { DapatDipelajari }\end{array}$ \\
\hline $\begin{array}{l}\text { Bagian badan dari stupa } \\
\text { pada pelataran delapan dan }\end{array}$ & $\begin{array}{r}\text { 1. Bentuk lubang - } \\
\text { lubang pada stupa } \\
\text { dapat digunakan }\end{array}$ \\
\hline
\end{tabular}

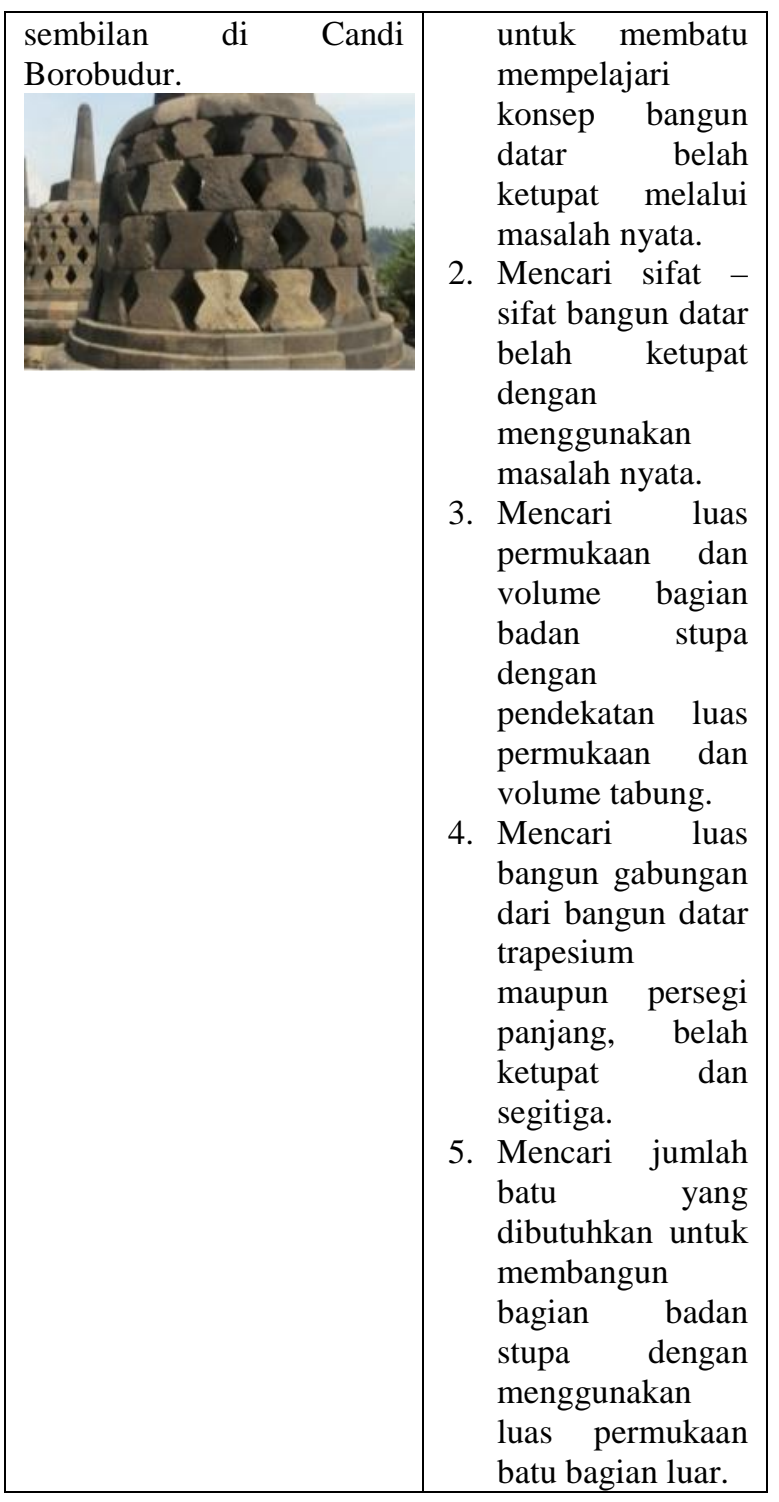

\section{c. Etnomatematika Konteks Kraton} Yogyakarta (Sumbaji, dkk, 2014)

\begin{tabular}{|l|ll|}
\hline \multicolumn{1}{|c|}{ Artefak } & \multicolumn{3}{|c|}{ Aspek Matematika } \\
\hline $\begin{array}{l}\text { Atap dalam arsitektur } \\
\text { keraton }\end{array}$ & $\begin{array}{l}\text { Silabus SMP tentang } \\
\text { bangun datar } \\
\text { Materi Pokok : Segitiga }\end{array}$ \\
& &
\end{tabular}




\begin{tabular}{|l|l|}
\hline menggunakan tabel, \\
grafik, dan persamaan \\
080402 Menggunakan \\
konsep perbandingan \\
untuk menyelesaikan \\
masalah nyata dengan \\
menggunakan tabel, \\
grafik, dan persamaan
\end{tabular}

\section{d. Etnomatematika Konteks Suku Dayak (Areani Eka Purti, 2014)}

Perisai (Tameng)
Perisai ini terbuat dari kayu
yang sudah dipilih kayu
yang diambil adalah kayu
yang tidak mudah rapuh
dan pecah, sehingga ketika
digunakan tidak mudah
retak atau patah. Tameng
ini digunakan saat akan
berperang r sebagai
pelindung. Juga biasa
digunakan saat menari
khususnya tarian perang.

Etnomatematik menggambarkan semua hal yang membentuk identitas budaya suatu kelompok, yaitu bahasa, kode, nilainilai, jargon, keyakinan, makanan dan pakaian, kebiasaan, dan sifat-sifat fisik. Sedangkan matematika mencakup pandangan yang luas mengenai aritmetika, mengklasifikasikan, mengurutkan, menyimpulkan, dan modeling. Etnomatematika berfungsi untuk mengekspresikan hubungan antara budaya dan matematika. Dengan demikian, etnomatematika adalah suatu pendekatan pengembangan pendidikan yang digunakan untuk mengkonstruksi bagaimana matematika diadaptasi dari sebuah budaya dan selanjutnya digunakan dalam kegiatan pembelajaran matematika.

\section{Kesimpulan}

Pengembangan Pendidikan Matematika kekinian diupayakan sedemikian sehingga pokok persoalan tetaplah apa yang dikerjakan siswa di dalam kelas, di mana guru mempunyai fungsi utama sebagai fasilitator atau peran melayani kebutuhan siswa untuk belajar matematika, yaitu membangun (konstruksi) pengetahuan matematikanya melalui berbagai fasilitas dan sumber belajar. Guru yang mempunyai peran penting, dalam setiap usaha inovasi pendidikan seyogyanya dalam posisi atau memeroleh keadaan sebagai berikut:

1. Guru merasa memperoleh pengetahuan baru tentang pembelajaran matematika

2. Guru merasa lebih mampu memfasilitasi belajar siswa yang mempunyai beraneka ragam

3. Guru merasa senang karena dapat mengembangkan matematika yang inovatif

4. Guru merasa lebih termotivasi untuk mengembangkan berbagai media pembelajaran.

5. Guru mampu mengembangkan dan melaksanakan pembelajaran matematika berbasis etnomatematika, memerlukan waktu yang lebih lama dan energi yang lebih banyak.

6. Guru mempunyai kesempatan untuk menguji benda-benda konkret dan obyek-obyek lingkungan sekitar dapat digunakan sebagai konteks pembelajaran matematika dalam membangun keterkaitan matematika melalui interaksi sosial.

7. Guru memperoleh kesempatan untuk menggali dan merefleksikan konsepkonsep pembelajaran matematika realistik.

8. Guru memperoleh kesempatan untuk bertukar pengalaman dengan guru lain tentang pengembangan pembelajaran matematika realistik.

9. Guru memperoleh kesempatan untuk merefleksikan persiapan proses belajar mengajar (PBM) matematika di sekolah melalui berbagai metode dan pendekatan.

10. Guru memperoleh kesempatan untuk merefleksikan pengembangan kegiatan asesmen untuk proses belajar mengajar (PBM) matematika di sekolah melalui berbagai macam metode dan pendekatan. 


\section{Daftar Pustaka}

Armando, D., and Stephen M., 2011, "Developing Learning Trajectory For Enhancing Students' Relational Thinking : International Seminar and the Fourth National Conference on Mathematics Education 2011 Department of Mathematics Education, Yogyakarta State UniversityYogyakarta, July 21-232011.

D'Ambrosio, U. 1991. 'Ethnomathematics and its place in the history and pedagogy of mathematics', in M. Harris (ed.). Schools, Mathematics and Work. The Falmer Press. London. pp. 15-25.

D'Ambrosio, U.: 1994. 'Cultural framing of mathematics teaching and learning', in R. Biehler, R.W. Scholz, R. Sträßer and B. Winklelmann (eds.). Didactics of Mathematics as a Scientific Discipline. Kluwer Academic Publishers. Dordrecht. pp. 443-455.

Ebbutt, S and Straker, A. 1995. Children and Mathematics: A Handbookfor Teacher, London: Collins Educational.

Gardner P. and Rix C., 2012, "Learning Trajectories of Primary Student Teachers; a Cross-Cultural Comparison", Journal of Social Sciences Volume 8, Issue 2 DOI : 10.3844/jssp.2012.135.142.

Marsigit, 2013, Urgensi Pemikiran Dalam Pendidikan Karakter Untuk Membentuk Karakter, Makalah dipresentasikan pada Seminar dan Lokakarya Kurikulum Fakultas Agama Karakter dan Pemikiran UNPAB Medan

Marsigit, 2013, Tantangan Dan Harapan Kurikulum 2013 Bagi Pendidikan Matematika, Makalah dipresentasikan pada Seminar Nasional Matematika dan Pendidikan Matematika, Universitas PGRI Yogyakarta.
Marsigit, 2013, Karakter Islam Dalam Sejarah Pergulatan Memperebutkan Kekuasaan, Filsafat, Ideologi, Ilmu(Matematika), Dan Pendidikan, Makalah Dipresentasikan pada Kuliah Umum (Studium Generale) untuk Mahasiswa Baru Tahun Akademik pada Jurusan Pendidikan Matematika, FITK UIN Syarif Hidayatullah Jakarta.

Marsigit, 2013, Pergulatan Memperebutkan Filsafat, Ideologi Dan Paradigma: Sebuah Kesadaran untuk Lembaga Pendidikan Ke Islaman dalam rangka ikut Membangun Karakter Bangsa (Melalui KKNI dan Kurikulum 2013?), Makalah dimaksudkan sebagai Pengantar Presentasi pada Kegiatan Seminar dan Workshop dengan Tema Membangun Karakter Bangsa dengan Pendidikan Melalui Kurikulum 2013 yang diselenggarakan oleh Fakultas Tarbiyah dan Keguruan, Universitas Negeri Sultan Syarif Kasim Riau.

Marsigit, 2013, Nilai Strategis Kurikulum 2013 Untuk Membangun Karakter (Islami) Bangsa Serta Tantangan Dan Harapan Bagi Pendidikan Matematika Di Indonesia, Makalah dipresentasikan pada Seminar Nasional dan Workshop Pendidikan Matematika IAIN Syekh Nurjati Cirebon.

Marsigit dan Rosnawati, 2014, Pengembangan Learning Trajectory dalam Pembelajaran matematika, FMIPA UNY.

Marsigit, dkk, 2013, Pengembangan Pembelajaran Matematika Berbasis Ethnomatematika, FMIPA UNY.

McLaren, P., 2004, Critical Theory in Education: Power, Politics and Liberation, Graduate School of Education and Information Studies: Los Angeles.

Rochel, C.R and Gelman G., 2005, "Mathematical Cognition" in In K Holyoak \& R. Morrison (Eds), The 
Cambridge handbook of thinking and reasoning: Cambridge University Press. 